\section{Madurez de la Revista Mexicana de Urología: continuidad y renovación}

Luis R. Beas Sandoval
Editor de la Revista Mexicana de Urología

Correspondencia:

Dr. Luis R. Beas Sandoval

urobeas@hotmail.com

DOI: https://doi.org/10.24245/revmexurol.v77i4.2029
En la asamblea del pasado LXVIII Congreso Nacional de la Sociedad Mexicana de Urología, efectuado en el puerto de Acapulco en noviembre de 2017, el Dr. Alfredo Medina Ocampo asumió la Presidencia del Consejo Directivo para el período 2017-2019. Así mismo, previo a la toma de protesta de la nueva mesa directiva se realizó la elección para designar al nuevo Editor de la Revista Mexicana de Urología para el período 2017-2020, otorgándome la membresía con su voto de confianza la distinción de ocupar dicho cargo y suplir al Dr. José Guzmán Esquivel, quien ha dejado una huella en la trayectoria de la revista, Ilena de logros como editor saliente.

La Revista Mexicana de Urología, por ser el órgano oficial de difusión de nuestra sociedad, es el espejo que refleja, en gran parte, la calidad de la urología mexicana. Es el organismo, dentro de nuestra sociedad, donde más se requiere la coincidencia de la continuidad y la renovación, y para que esto suceda es necesaria: la madurez, de la cual goza la Revista Mexicana de Urología, pues en 2018 cumple su 75 aniversario, desde que se publicó el número 1 impreso correspondiente a los meses de enero-febrero de 1943, con el editorial escrito por su primer editor: Dr. Arturo Lara Rivas y con la presidencia del Dr. Aquilino Villanueva Arreola, quien tuvo el honor de publicar el primer artículo en nuestra revista.

Desde entonces se han designado 19 editores, incluido el actual, todos dispuestos a enfrentar los retos, que en su esencia, a pesar del tiempo, prácticamente siguen siendo los mismos y quienes han colaborado como editores, lo han hecho conscientes de que en esta labor se debe ceder el tiempo de descanso por el entusiasmo que genera la satisfacción de cumplir con su tarea al editar, publicar y distribuir en forma regular y sin interrupciones cada número de la Revista Mexicana de Urología, con el contenido de los artículos que han sido enviados en su mayoría por urólogos de la Sociedad Mexicana de Urología.

La continuidad entre los editores se ha reflejado en la calidad de la revista, que ha ido aumentando progresivamente al paso de los años, tal vez más lento de lo esperado, debido a que intervienen factores culturales, sociales y económicos adicionales, propios de nuestro país; sin embargo, a pesar de ello se ha logrado tener la revista arbitrada y con mayor visibilidad, pues se encuentra indizada en varios repositorios importantes que ofrecen métricas precisas de su comportamiento y citación, y de esta 
manera dar pasos importantes hacia un mayor reconocimiento.

Para lograr la meta trazada desde hace varios años, de escalar a los niveles de los mejores escaparates científicos de las publicaciones médicas, debe darse continuidad a lo avanzado y en la medida que los investigadores sigan colaborando mediante el envío de trabajos de mayor nivel de evidencia, es obvio que la evaluación de la Revista Mexicana de Urología se incrementará, incluso si nos renovamos con la ayuda de los avances tecnológicos en comunicación, para de esta forma facilitar los procesos con el acceso digital y lograr difundir con mayor rapidez la visibilidad. Esto favorecerá las gestiones a corto y mediano plazo que se requieren para tener un mejor posicionamiento de la Revista Mexicana de Urología.

En los pasos señalados se requiere la colaboración de todos los socios de la Sociedad Mexicana de Urología, con la finalidad de mantenerse atentos de las publicaciones en el nuevo formato digital y ayudar a su difusión en todos los medios electrónicos. Así mismo, la Revista Mexicana de Urología debe concebirse como una empresa en la que deben asignarse recursos de diferente índole, para elaborar un producto donde la "materia prima" consiste en los artículos que envían los autores, que llenos de conocimiento ingresan a un proceso donde el editor, grupo editorial y revisores intervienen para crear un "flujo editorial" que genera a la revista un "producto final", lista para distribuirla y que el producto sea evaluado por los lectores nacionales e internacionales, además de los índices que miden la calidad.

Tengo conocimiento de la función del editor, pues está documentado de una forma general por la Asociación Mundial de Editores Médicos (WAME) en 12 puntos, denominados los "XII Mandamientos del Editor", que a continuación señalo:

\section{El Editor es responsable de:}

I. Conocer las necesidades e intereses de los lectores.

II. La preservación de los derechos para investigación de sujetos y animales.

III. El contenido editorial.

IV. La definición de políticas editoriales para autoría y sumisión de trabajos para la revista.

V. El establecimiento y mantenimiento de un flujo de revisión por pares para la selección de trabajos.

VI. La integridad de los autores y la confidencialidad de los trabajos en proceso de revisión.

VII. Tomar decisiones y sostenerlas, pero también reconsiderarlas cuando apropiado.

VIII. Trabajar para mejorar la calidad de los trabajos y de la investigación en su área de conocimiento.

IX. Estar preparados para enfrentar alegaciones de errores y mala conducta científica.

X. Mantener independencia editorial y trabajar para que los autores tengan libertad editorial.

XI. Evitar conflictos personales, financieros o de cualquier tipo relacionados con su responsabilidad como editor.

XII. Elaborar un plan estratégico para el futuro de la revista.

Estoy consciente de mi responsabilidad y compromiso en cada punto señalado; así mismo, agradezco a todos la postulación y apoyo para ser editor, por segunda ocasión, pues con esto me brindan una nueva oportunidad para mejorar y servir a todos, en conjunto con los miembros del consejo directivo, autores, colaboradores editoriales, revisores y lectores. 